\title{
Blood neurofilament light chain as a biomarker of MS disease activity and treatment response
}

Jens Kuhle, MD,* Harald Kropshofer, PhD,* Dieter A. Haering, PhD, Uma Kundu, MPharm, Rolf Meinert, PhD, Christian Barro, MD, Frank Dahlke, MD, Davorka Tomic, PhD, David Leppert, MD, and Ludwig Kappos, MD

Neurology ${ }^{\circledR}$ 2019;92:e1007-e1015. doi:10.1212/WNL.0000000000007032

\section{Abstract}

\section{Objective}

To assess the value of blood neurofilament light chain (NfL) as a biomarker of recent, ongoing, and future disease activity and tissue damage and its utility to monitor treatment response in relapsing-remitting multiple sclerosis.

\section{Methods}

We measured NfL in blood samples from 589 patients with relapsing-remitting multiple sclerosis (from phase 3 studies of fingolimod vs placebo, FREEDOMS and interferon [IFN]$\beta$-1a, TRANSFORMS) and 35 healthy controls and compared NfL levels with clinical and MRI-related outcomes.

\section{Results}

At baseline, NfL levels $(\mathrm{pg} / \mathrm{mL})$ were higher in patients than in healthy controls (30.5 and 27.0 vs $16.9, p=0.0001$ ) and correlated with T2 lesion load and number of gadolinium-enhancing T1 lesions ( $p<0.0001$, both). Baseline NfL levels, treatment, and number of new or enlarging T2 lesions during the studies predicted NfL levels at the end of study (all $p<0.01$ ). High vs low baseline NfL levels were associated (estimate [95\% confidence interval]) with an increased number of new or enlarging T2 lesions (ratio of mean: 2.64 [1.51-4.60]; $p=0.0006$ ), relapses (rate ratio: $2.53[1.67-3.83] ; p<0.0001$ ), brain volume loss (difference in means: $-0.78 \%$ $[-1.02$ to -0.54$] ; p<0.0001$ ), and risk of confirmed disability worsening (hazard ratio: 1.94 [0.97-3.87]; $p=0.0605)$. Fingolimod significantly reduced NfL levels already at 6 months (vs placebo 0.73 [0.656-0.813] and IFN 0.789 [0.704-0.884]), which was sustained until the end of the studies (vs placebo 0.628 [0.552-0.714] and IFN 0.794 [0.705-0.894]; $p<0.001$, both studies at all assessments).

\section{Conclusions}

Blood NfL levels are associated with clinical and MRI-related measures of disease activity and neuroaxonal damage and have prognostic value. Our results support the utility of blood NfL as an easily accessible biomarker of disease evolution and treatment response.

\author{
Correspondence \\ Dr. Kuhle \\ Jens.Kuhle@usb.ch
}

\section{RELATED ARTICLE}

\section{Editorial}

Neurofilament light chain: An important step toward a disease biomarker in multiple sclerosis

Page 451

*These authors contributed equally to this work.

From the Neurologic Clinic and Policlinic (J.K., C.B., L.K.), Departments of Medicine, Biomedicine and Clinical Research, University Hospital Basel, University of Basel; Novartis Pharma AG (H.K., D.A.H., F.D., D.T., D.L.), Basel, Switzerland; Novartis Healthcare Pvt. Ltd. (U.K.), Hyderabad, India; and DATAMAP GmbH (R.M.), Freiburg, Germany.

Go to Neurology.org/N for full disclosures. Funding information and disclosures deemed relevant by the authors, if any, are provided at the end of the article. 


\section{Glossary}

CDW = confirmed disability worsening; CV = coefficient of variation; EDSS = Expanded Disability Status Scale; EOS = end of study; FREEDOMS = Efficacy and Safety of Fingolimod in Patients with Relapsing-Remitting Multiple Sclerosis; Gd = gadolinium; GeoMean = geometric mean; IFN = interferon; ITT = intention-to-treat; $\mathbf{M S}=$ multiple sclerosis; NfL = neurofilament light chain; RRMS = relapsing-remitting multiple sclerosis; SIMOA = single molecule array; TRANSFORMS = Efficacy and Safety of Fingolimod in Patients with Relapsing-Remitting Multiple Sclerosis with Optional Extension Phase.

MRI is the current standard to quantitate brain atrophy as a macroscopic reflection of the neuroaxonal damage occurring in patients with multiple sclerosis (MS). ${ }^{1}$ However, MRI assessments of brain volume loss are difficult to standardize and are retrospective in nature. ${ }^{2}$ Therefore, there is a need for easier-to-perform and less costly biomarkers suitable for longitudinal monitoring of the disease in clinical trials and in routine clinical practice.

Elevated CSF and blood concentrations of neurofilament light chain (NfL) were found to correlate with an increase in the number of relapses, disability worsening, MRI disease activity, and brain volume loss in MS. ${ }^{3-9}$ A highly sensitive single molecule array (SIMOA) immunoassay has recently been developed to measure NfL in blood. ${ }^{6,10}$ Blood NfL measured with SIMOA was shown to strongly correlate with $\mathrm{NfL}$ in the CSF of patients with MS. ${ }^{6-9}$

We therefore assessed NfL as a potential biomarker to monitor MS disease activity and treatment response using blood samples obtained in the course of 2 large, phase 3, randomized controlled clinical trials of fingolimod in relapsing-remitting MS (RRMS). Our objectives were as follows: (1) compare blood NfL concentrations in patients with RRMS to those in healthy controls; (2) assess the relationship of NfL concentrations with patient demographics and MS disease characteristics cross-sectionally; (3) evaluate the effect of fingolimod on blood NfL concentrations compared to placebo or interferon (IFN)- $\beta$-1a; and (4) investigate the prognostic potential of blood NfL at baseline for future disease activity and disease worsening.

\section{Methods}

\section{Participants}

\section{Patients with MS}

In this exploratory biomarker analysis, we measured NfL concentrations in blood samples from patients with RRMS who participated in the 2-year, placebo-controlled, phase 3 FREEDOMS trial ${ }^{11}$ (NCT00289978) and the 1-year, activecontrolled, phase 3 TRANSFORMS trial ${ }^{12}$ (NCT00340834). Patients had to stop IFN- $\beta$ or glatiramer acetate therapy 3 or more months before inclusion in FREEDOMS, whereas no washout was required before inclusion in TRANSFORMS.

\section{Healthy controls}

We measured NfL concentrations in blood samples from 35 healthy controls of similar age.

\section{Assessments}

In FREEDOMS, blood samples were collected at baseline and months $6,12,18$, and 24, and in TRANSFORMS, at baseline and months 6 and 12. All available blood samples from consenting patients who received fingolimod $0.5 \mathrm{mg}$, placebo, or IFN- $\beta$-1a were analyzed. We measured the concentrations of $\mathrm{NfL}$ in ethylenediaminetetraacetic acid-treated plasma samples using the SIMOA immunoassay described previously. ${ }^{6}$ Interassay coefficients of variation (CVs) for 3 native plasma samples were below $12 \%$. The mean intra-assay $\mathrm{CV}$ of duplicate determinations for concentration was $4.9 \%$. Repeat measurements were done for a few samples with intra-assay $\mathrm{CVs}$ above $20 \%$. Measurements were performed on coded samples. All laboratory personnel remained blinded to treatment allocation and diagnosis and had no access to clinical data.

\section{Statistical analysis}

\section{NfL measurements}

We analyzed data according to the intention-to-treat (ITT) principle and included all available values in the statistical analysis. We summarized NfL concentrations using geometric means (GeoMeans) and compared them between healthy controls and patients with MS using a Wilcoxon rank sum test.

\section{Demographic and MS disease characteristics related to $\mathrm{NfL}$}

To identify the best explanatory factors of baseline NfL concentrations among baseline MS disease and demographic variables, a multiple linear regression analysis of $\log (\mathrm{NfL})$ on 8 candidate variables was conducted: age, sex, disease duration since first symptoms, MS treatment prior to randomization (yes/no), relapses in the past 60 days before the collection of the blood sample (yes/no), Expanded Disability Status Scale (EDSS) score at baseline, gadolinium-enhancing $(\mathrm{Gd}+)$ lesion count at baseline, and $\mathrm{T} 2$ lesion volume at baseline. GeoMean ratios are reported with $95 \%$ confidence intervals and $p$ values. For Nfl concentrations at end of study (EOS), analogous linear regression analyses were performed whereby the potential baseline explanatory variables "prior MS treatment" and "EDSS" were dropped and "treatment," "new T2 lesions on study," and "log-transformed $(\log )$ baseline NfL" were included as additional explanatory variables. The underlying assumptions of the linear regression models (linearity, normality, and homoscedasticity) were checked and deemed acceptable in regression diagnostic plots.

\section{Treatment effect}

The treatment effect of fingolimod on NfL vs placebo in FREEDOMS, or vs IFN- $\beta$ - $1 \mathrm{a}$ in TRANSFORMS, was 
visualized in line plots with GeoMeans and their 95\% confidence intervals, which were obtained from a mixed model for repeated measurements with $\log (\mathrm{NfL})$ as the response variable and with adjustments for treatment, age, and $\log$ (baseline $\mathrm{NfL}$ ). The model further included visit-by-treatment and visitby-log(baseline NfL) interactions. An unstructured covariance matrix was used. Model assumptions were checked in regression diagnostic plots and deemed acceptable.

A sensitivity analysis using multiple regression models of $\log (\mathrm{NfL})$ with adjustments for treatment, age, and $\log$ (baseline $\mathrm{NfL}$ ) fit by time point provided similar results.

\section{Prognostic potential of baseline NfL concentrations for on-study activity and disease worsening}

To investigate the prognostic potential of NfL on MS disease activity and worsening, patients were grouped by treatment and NfL category to quantify and illustrate MS outcomes within distinct subgroups of patients. Patients from the 2-year FREEDOMS study were categorized into 3 groups based on their baseline NfL concentration: low, $<30 \mathrm{pg} / \mathrm{mL}$; medium, 30-60 $\mathrm{pg} / \mathrm{mL}$; and high, $>60 \mathrm{pg} / \mathrm{mL}$. The cutoff at $30 \mathrm{pg} / \mathrm{mL}$ corresponds to the GeoMean in patients with relapsing MS in our dataset and is approximately twice as high as the value seen in healthy controls; the cutoff at $60 \mathrm{pg} / \mathrm{mL}$ corresponds to approximately twice the GeoMean in patients with relapsing MS. Descriptive statistics for each group were calculated for each endpoint. The number of new or enlarging T2 lesions, and the annualized relapse rate were both analyzed in negative binomial models, the annualized rate of brain volume change (measured using SIENA [Structural Image Evaluation, Using Normalization, of Atrophy] as previously described ${ }^{13}$ ) in a linear regression model, and time to 3-month confirmed disability worsening (CDW) in a Cox proportional hazard model. We adjusted each model for treatment and NfL category at baseline and for additional covariates (detailed later). In a second step, we expanded each model by a treatment-by-NfL category interaction to test whether the NfL effect varies across treatment arms and whether the treatment effect depends on NfL category.

\section{Data availability}

Anonymized data not published within this article will be made available by request from any qualified investigator.

\section{Results}

\section{Baseline characteristics}

Blood samples of 269 patients from the FREEDOMS trial and 320 patients from the TRANSFORMS trial were available for this analysis, reflecting $23 \%$ of the ITT population of these trials. Availability of samples was exclusively related to the patients' informed consent for this biomarker study and unrelated to clinical study outcomes. Baseline demographic and disease characteristics of the patients who contributed to this analysis were similar across treatment groups and to the overall randomized population of the respective trials. The analyzed population was young (mean [SD] age was 37.1 [8.6] and 36.5 [8.2] years) and predominately comprised women $(69.1 \%$ and $67.2 \%$ of the total analysis population). The mean (SD) disease duration since first symptom was 8.1 (6.1) and 7.8 (6.4) years for FREEDOMS and TRANSFORMS, respectively. The patients on average experienced 2.1 (1.2) and 2.2 (1.3) number of relapses in the last 2 years before randomization to the respective trials. The mean (SD) EDSS score was 2.5 (1.3) and 2.2 (1.3), mean number of Gd+ lesions were 1.5 (3.6) and $0.9(2.6)$, mean T2 lesion volume $\left(\mathrm{cm}^{3}\right)$ was $6.732(7.535)$ and $4.829(5.842)$, and the normalized brain volume $\left(\mathrm{cm}^{3}\right)$ was $1,512(85.3)$ and $1,526(75.3)$.

Figure 1 Baseline NfL concentrations in patients with relapsing-remitting multiple sclerosis and healthy controls

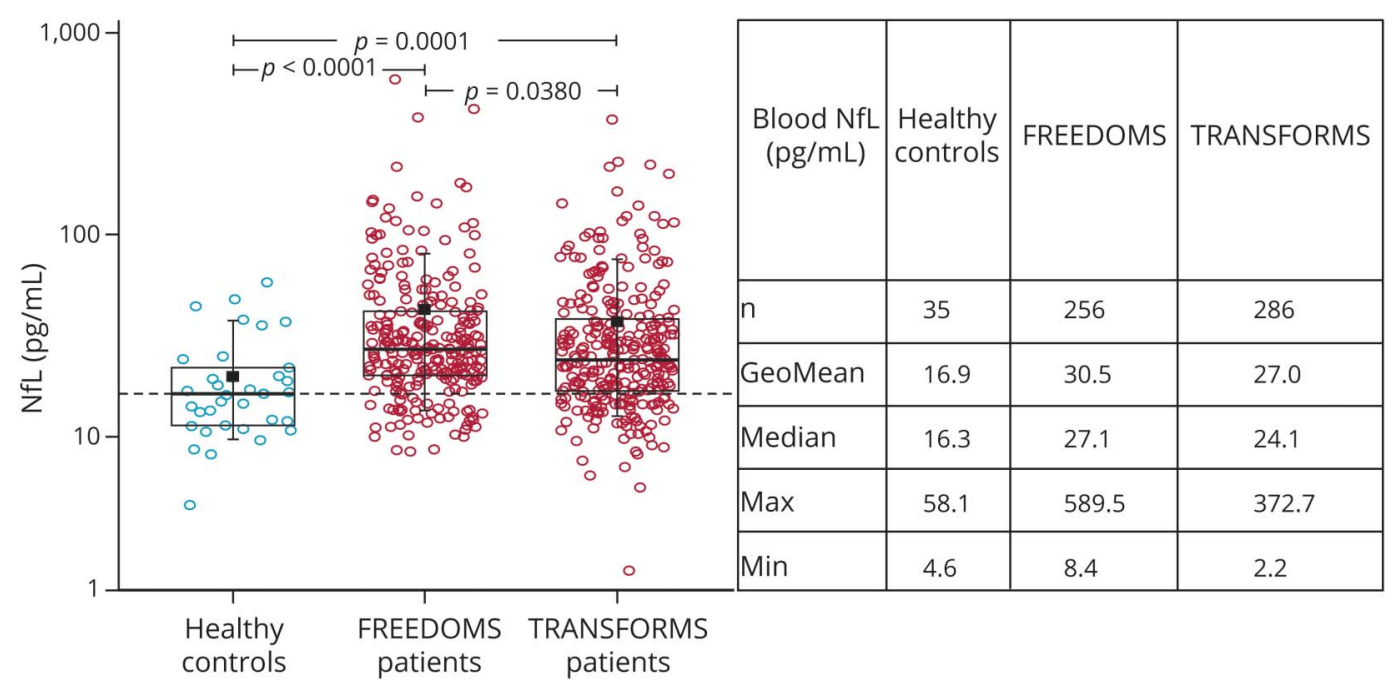

The box represents the interquartile range, with the median represented by the line in the center; $n=$ number of patients with evaluable data. The black dot represents the GeoMean value and the whiskers indicate the $10^{\text {th }}$ and $90^{\text {th }}$ percentiles. Dotted line represents plasma NfL (pg/mL, median) concentrations in healthy controls. The $p$ Values are based on a Wilcoxon rank sum test. GeoMean = geometric mean; Max = maximum; Min = minimum; NfL = neurofilament light chain. 
Table 1 Relationship between NfL levels and MS characteristics at baseline

\begin{tabular}{|c|c|c|c|c|c|c|}
\hline \multirow[b]{2}{*}{ Disease parameter } & \multicolumn{3}{|c|}{ FREEDOMS $(n=269)$} & \multicolumn{3}{|c|}{ TRANSFORMS $(n=320)$} \\
\hline & $\begin{array}{l}\text { GeoMean } \\
\mathrm{NfL}, \mathrm{pg} / \mathrm{mL}\end{array}$ & $\begin{array}{l}\text { GeoMean } \\
\text { ratio }(95 \% \mathrm{Cl})\end{array}$ & $p$ Value & $\begin{array}{l}\text { GeoMean } \\
\mathrm{NfL}, \mathrm{pg} / \mathrm{mL}\end{array}$ & $\begin{array}{l}\text { GeoMean } \\
\text { ratio }(95 \% \mathrm{Cl})\end{array}$ & $p$ Value \\
\hline Age, y & & $0.997(0.987-1.006)$ & 0.5005 & & $1.002(0.992-1.013)$ & 0.6742 \\
\hline \multicolumn{7}{|l|}{ Sex } \\
\hline Male & 32.5 & $1.038(0.883-1.221)$ & 0.6479 & 32.0 & $1.035(0.878-1.221)$ & 0.6796 \\
\hline Female & 31.3 & & & 30.9 & & \\
\hline $\begin{array}{l}\text { Duration of disease since } \\
\text { first symptoms, y }\end{array}$ & & $0.982(0.969-0.996)$ & $0.0096^{a}$ & & $0.986(0.971-1.000)$ & $0.0534^{a}$ \\
\hline \multicolumn{7}{|l|}{ Prior MS treatment } \\
\hline No & 32.7 & $0.952(0.815-1.113)$ & 0.5366 & 34.5 & $0.829(0.695-0.990)$ & $0.0379^{a}$ \\
\hline Yes $^{\mathbf{b}}$ & 31.1 & & & 28.6 & & \\
\hline \multicolumn{7}{|l|}{ Relapses in past $60 \mathrm{~d}$} \\
\hline Yes & 32.4 & $1.034(0.853-1.254)$ & 0.7311 & 34.9 & $1.237(1.020-1.501)$ & $0.0311^{a}$ \\
\hline No & 31.4 & & & 28.2 & & \\
\hline EDSS score & & $1.061(0.990-1.136)$ & 0.0920 & & $1.038(0.970-1.111)$ & 0.2759 \\
\hline \multicolumn{7}{|l|}{ Gd+ T1 lesions } \\
\hline Present & 40.9 & $1.642(1.398-1.930)$ & $<0.0001^{a}$ & 38.2 & $1.480(1.251-1.752)$ & $<0.0001^{a}$ \\
\hline Absent & 24.9 & & & 25.8 & & \\
\hline T2 lesion volume, $\mathrm{cm}^{3}$ & & $1.027(1.016-1.039)$ & $<0.0001^{a}$ & & $1.039(1.025-1.054)$ & $<0.0001^{a}$ \\
\hline
\end{tabular}

Abbreviations: $\mathrm{Cl}$ = confidence interval; EDSS = Expanded Disability Status Scale; Gd+ = gadolinium-enhancing; GeoMean = geometric mean; MS = multiple sclerosis; NfL = neurofilament light chain plasma level.

All estimates are from a multiple linear regression model of $\log (\mathrm{NfL})$ on 8 explanatory parameters: (1) duration of disease since first symptoms, (2) prior $\mathrm{MS}$ treatment, (3) relapses in the past 60 days prior to study entry, (4) presence of Gd+ lesions on the screening scan, (5) baseline T2 lesion volume, (6) age, (7) sex, and (8) baseline EDSS score. The interpretation of the relationship of each parameter and NfL is after adjusting for all other variables in the multiple regression model. For qualitative explanatory parameters, the GeoMean ratio represents a multiplier of the GeoMean NfL when changing from one category of the explanatory parameter to the next. For continuous explanatory parameters, the GeoMean ratio represents the extent of change in NfL levels when the corresponding explanatory parameter increases by 1 unit.

a $p<0.05$ signifies a significant relationship between the GeoMean NfL (pg/mL) and the explanatory parameter.

b Previous treatment with glatiramer acetate or interferon- $\beta$. In FREEDOMS, patients who were previously treated with interferon- $\beta$ and glatiramer acetate had to stop this treatment 3 months before baseline, while in TRANSFORMS, they could be included without prior washout.

\section{Association of NfL at baseline with other baseline disease characteristics}

At baseline, patients had significantly higher blood Nfl concentrations (FREEDOMS $30.5 \mathrm{pg} / \mathrm{mL}$, TRANSFORMS 27.0 $\mathrm{pg} / \mathrm{mL})$ than healthy controls $(16.9 \mathrm{pg} / \mathrm{mL}, p=0.0001$ in both trials; figure 1). Patients who switched from IFN or glatiramer acetate directly to TRANSFORMS had lower NfL values than treatment-naive patients (28.6 vs $34.5 \mathrm{pg} / \mathrm{mL}, p=0.0379$ ); there was no statistically significant difference of NfL levels between previously treated and treatment-naive patients in FREEDOMS (31.1 vs $32.7 \mathrm{pg} / \mathrm{mL}, p=0.5366$; table 1 ).

In a multiple linear regression model, which included 8 potential explanatory variables, high baseline NfL concentrations were strongly associated with high baseline $\mathrm{T} 2$ lesion volume and the presence of $\mathrm{Gd}+\mathrm{T} 1$ lesions (table 1 ). In patients with very low T2 lesion volume $\left(<0.8 \mathrm{~cm}^{3}\right)$, NfL concentrations were similar to the levels of healthy controls. NfL concentrations increased gradually with higher baseline T2 lesion volume (figure 2). Per cubic-centimeter increase in T2 lesion volume, NfL levels increased by $2.7 \%$ (FREEDOMS) and 3.9\% (TRANSFORMS).

In both studies, NfL concentrations were higher in patients with $\mathrm{Gd}+$ lesions at baseline compared with those free of $\mathrm{Gd}+$ lesions (FREEDOMS: 40.9 vs $24.9 \mathrm{pg} / \mathrm{mL}, p<0.0001$; TRANSFORMS: 38.2 vs $25.8 \mathrm{pg} / \mathrm{mL}, p<0.0001)$. The adjusted NfL concentrations were 64\% ( $p<0.0001$, FREEDOMS $)$ and $48 \%$ $(p<0.0001$, TRANSFORMS $)$ higher in patients with Gd+ lesions than in patients without $\mathrm{Gd}+$ lesions (table 1). Adjusted $\mathrm{NfL}$ values ranged from $22.9 \mathrm{pg} / \mathrm{mL}$ in patients without $\mathrm{Gd}+$ lesions to $75.5 \mathrm{pg} / \mathrm{mL}$ in patients with more than $3 \mathrm{Gd}+$ lesions in FREEDOMS; in TRANSFORMS, the corresponding values were 22.8 and $62.2 \mathrm{pg} / \mathrm{mL}$, respectively $(p<0.0001$, both trials) (figure 3). Patients without $\mathrm{Gd}+$ lesions at baseline also had significantly higher NfL concentrations than healthy controls ( $p=0.0014$; pooled trial cohorts). Association of baseline NfL 
Figure 2 Blood NfL levels by T2 lesion volume $\left(\mathrm{mm}^{3}\right)$ at baseline: (A) FREEDOMS, (B) TRANSFORMS

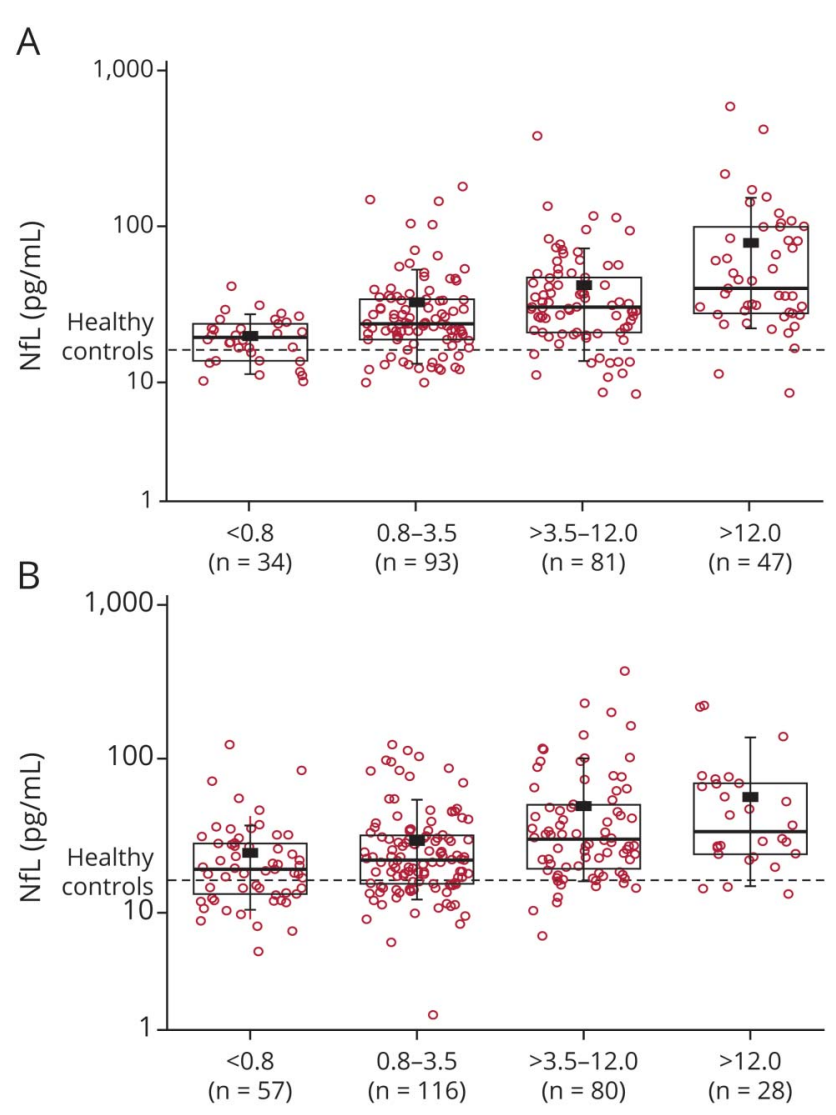

The box represents the interquartile range, with the median represented by the line in the center; $n=$ number of patients with evaluable data. The black dot represents the geometric mean value and the whiskers indicate the $10^{\text {th }}$ and $90^{\text {th }}$ percentiles. Dotted line represents plasma NfL $(\mathrm{pg} / \mathrm{mL}$, median) concentrations in healthy controls. $\mathrm{NfL}=$ neurofilament light chain.

concentration with disease duration was only significant in FREEDOMS and the presence of recent relapses or a prior disease-modifying treatment in TRANSFORMS; we did not find significant associations of baseline NfL concentrations with age, sex, and EDSS score at baseline (table 1).

\section{Patient and disease parameters predictive of $\mathrm{NfL}$ at EOS}

The strongest prognostic factor of high NfL at EOS was a high $\mathrm{NfL}$ at baseline $(p<0.0001$ in both trials; table 2$)$. Independent of treatment, patients with high NfL levels at baseline had higher NfL levels at EOS than patients with low NfL concentrations at baseline. Moreover, occurrence of new or enlarging $\mathrm{T} 2$ lesions during the studies was also associated with higher $\mathrm{NfL}$ at EOS ( $p<0.001$, both trials). Fingolimod treatment significantly reduced NfL levels at EOS compared with placebo or IFN- $\beta$-1a $(p<0.01$, both trials). Older patients had higher NfL concentrations at EOS in FREEDOMS $(p=0.0002)$; however, this association could not be confirmed in the TRANSFORMS study $(p=0.1239)$. All other variables (sex, disease duration, relapses in the past 60 days before the NfL
Figure 3 Blood NfL levels by Gd+ T1 lesion count at baseline: (A) FREEDOMS, (B) TRANSFORMS

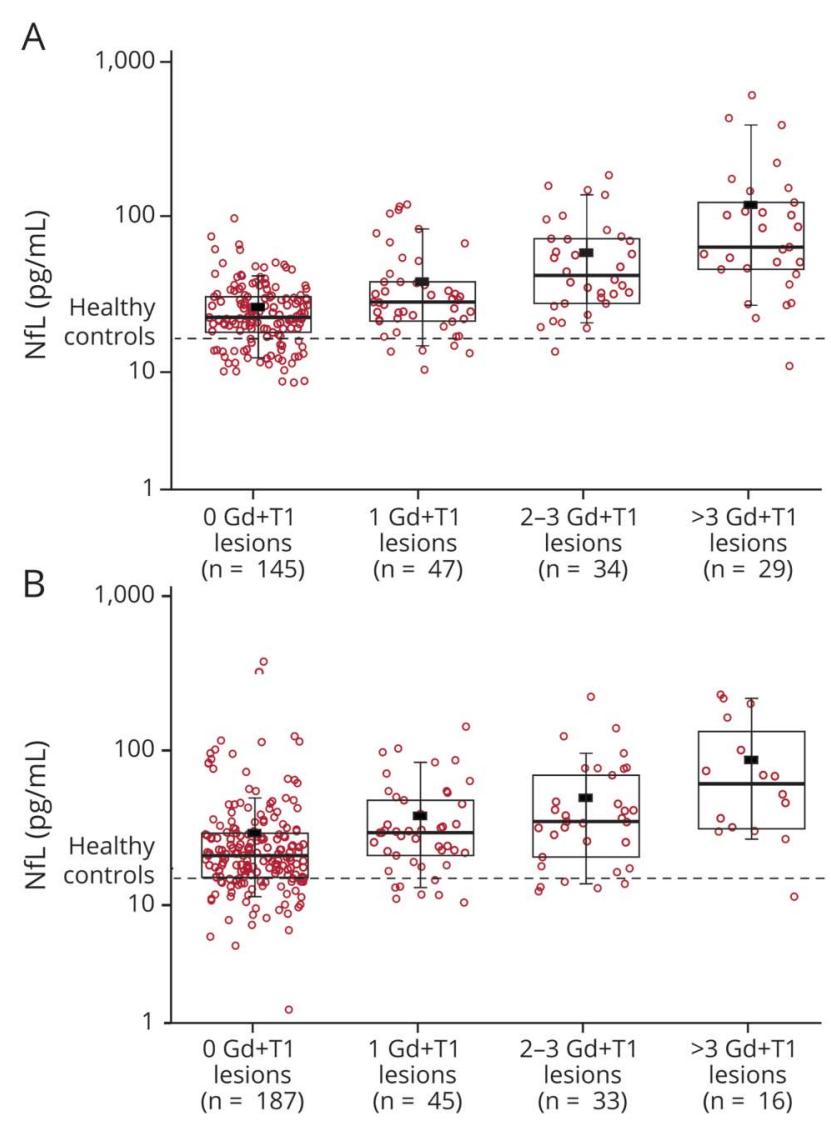

The box represents the interquartile range, with the median represented by the line in the center; $n=$ number of patients with evaluable data. The black dot represents the geometric mean value and the whiskers indicate the $10^{\text {th }}$ and $90^{\text {th }}$ percentiles. Dotted line represents plasma $\mathrm{NfL}(\mathrm{pg} / \mathrm{mL}$, median) concentrations in healthy controls. $\mathrm{Gd}+=$ gadolinium-enhancing; $\mathrm{NfL}=$ neurofilament light chain.

sampling date at EOS, the number of $\mathrm{Gd}+$ lesions at baseline, and $\mathrm{T} 2$ lesion volume) had no additional explanatory value for the EOS NfL concentration (table 2).

\section{$\mathrm{NfL}$ is sensitive to treatment}

In the first $\mathrm{NfL}$ assessment, 6 months after start of study treatment, blood NfL concentrations in the fingolimod group were significantly lower compared with both placebo and IFN- $\beta$-1a (figure 4, A and B). In FREEDOMS, blood $\mathrm{NfL}$ concentrations in the fingolimod group decreased by $35.4 \%$ at month 6 relative to baseline $(30.6-19.6 \mathrm{pg} / \mathrm{mL})$ and by $43 \%$ at month $24(31.4-18.0 \mathrm{pg} / \mathrm{mL})$, whereas in the placebo group, the reduction was $9 \%(29.1-26.7 \mathrm{pg} / \mathrm{mL})$ and $4 \%(28.2-26.9 \mathrm{pg} / \mathrm{mL})$, respectively. In TRANSFORMS, blood NfL concentrations in the fingolimod arm decreased by $36 \%(28.5-18.4 \mathrm{pg} / \mathrm{mL})$ at month 6 , and by $39 \%$ at month $12(28.2-17.1 \mathrm{pg} / \mathrm{mL})$. The corresponding reductions in the IFN- $\beta-1 \mathrm{a}$ arm were $14 \%(24.8-21.5 \mathrm{pg} /$ $\mathrm{mL}$ ) and $17 \%(24.9-20.7 \mathrm{pg} / \mathrm{mL})$. By EOS, NfL levels in fingolimod-treated patients were approaching those of healthy controls $(16.9 \mathrm{pg} / \mathrm{mL})$ in both trials. 
Table 2 NfL levels at end of study by demographic, clinical, and MRI characteristics

\begin{tabular}{|c|c|c|c|c|c|c|}
\hline \multirow[b]{2}{*}{ Patient and disease parameters } & \multicolumn{3}{|c|}{ FREEDOMS $(n=269)$} & \multicolumn{3}{|c|}{ TRANSFORMS $(\mathrm{n}=320)$} \\
\hline & $\begin{array}{l}\text { GeoMean NfL, } \\
\mathrm{pg} / \mathrm{mL}\end{array}$ & $\begin{array}{l}\text { GeoMean ratio } \\
(95 \% \mathrm{Cl})\end{array}$ & $p$ Value & $\begin{array}{l}\text { GeoMean NfL, } \\
\mathrm{pg} / \mathrm{mL}\end{array}$ & $\begin{array}{l}\text { GeoMean ratio } \\
(95 \% \mathrm{Cl})\end{array}$ & $p$ Value \\
\hline Age, y & & $1.015(1.007-1.023)$ & $0.0002^{\mathrm{a}}$ & & 1.007 (0.998-1.015) & 0.1239 \\
\hline \multicolumn{7}{|l|}{ Sex } \\
\hline Male & 17.9 & $0.893(0.775-1.029)$ & 0.1160 & 18.9 & $0.950(0.832-1.085)$ & 0.4460 \\
\hline Female & 20.0 & & & 19.9 & & \\
\hline $\begin{array}{l}\text { Duration of disease since first } \\
\text { symptoms, y }\end{array}$ & & $0.998(0.987-1.009)$ & 0.7117 & & $1.000(0.988-1.012)$ & 0.9780 \\
\hline \multicolumn{7}{|l|}{ Relapses in past $60 \mathrm{~d}$} \\
\hline Yes & 17.3 & $0.838(0.615-1.143)$ & 0.2624 & 19.9 & $1.051(0.830-1.332)$ & 0.6766 \\
\hline No & 20.7 & & & 18.9 & & \\
\hline \multicolumn{7}{|l|}{ Treatment } \\
\hline Fingolimod & 15.8 & $0.697(0.609-0.798)$ & $<0.0001^{\mathrm{a}}$ & 17.6 & $0.828(0.731-0.938)$ & $0.0032^{\mathrm{a}}$ \\
\hline Control $^{\mathbf{b}}$ & 22.7 & & & 21.3 & & \\
\hline \multicolumn{7}{|l|}{ Gd+ T1 lesions } \\
\hline Present & 18.7 & $0.970(0.836-1.125)$ & 0.6877 & 20.0 & $1.068(0.926-1.232)$ & 0.3666 \\
\hline Absent & 19.2 & & & 18.7 & & \\
\hline \multicolumn{7}{|l|}{ New/enlarging $\mathrm{T} 2$ lesions on study } \\
\hline Yes & 21.8 & $1.319(1.136-1.531)$ & $0.0003^{a}$ & 22.3 & $1.325(1.163-1.509)$ & $<0.0001^{a}$ \\
\hline No & 16.5 & & & 16.8 & & \\
\hline T2 lesion volume, $\mathrm{cm}^{3}$ & & $1.002(0.992-1.011)$ & 0.7146 & & $1.002(0.989-1.014)$ & $0.7759^{a}$ \\
\hline Log(baseline NfL) & & & $<0.0001^{a}$ & & & $<0.0001^{a}$ \\
\hline \multicolumn{7}{|c|}{$\begin{array}{l}\text { Abbreviations: } \mathrm{Cl}=\text { confidence interval; Gd+ } \mathrm{Gd} \text { gadolinium-enhancing; GeoMean = geometric mean; } \mathrm{NfL}=\text { neurofilament light chain plasma level. } \\
\text { All estimates are from a multiple linear regression of log(NfL) on } 8 \text { explanatory parameters: (1) duration of multiple sclerosis, (2) prior multiple sclerosis } \\
\text { treatment, (3) relapses in the past } 60 \text { days prior to NfL assessment at end of study, (4) presence of Gd+ lesions on the screening scan, (5) baseline T2 lesion } \\
\text { volume, (6) age, (7) Sex, and (8) baseline Expanded Disability Status Scale score. The interpretation of the relationship of each parameter and NfL is after } \\
\text { adjusting for all other variables in the multiple regression model. For qualitative explanatory parameters, the GeoMean ratio represents a multiplier of the } \\
\text { GeoMean NfL when changing from one category of the explanatory parameter to the next. For continuous explanatory parameters, the GeoMean ratio } \\
\text { represents the extent of change in NfL levels when the corresponding explanatory parameter increases by } 1 \text { unit. } \\
\text { a } p<0.05 \text { signifies a significant relationship between the GeoMean NfL (pg/mL) and the explanatory factor when adjusting for all the other variables in the } \\
\text { multiple regression model. } \\
\text { b Control is placebo in FREEDOMS and intramuscular interferon- } \beta-1 \text { a in TRANSFORMS. }\end{array}$} \\
\hline
\end{tabular}

\section{Prognostic potential of baseline NfL for future disease activity and worsening}

We investigated the prognostic value of 3 categories of baseline blood NfL concentrations for on-study lesion formation, relapse activity, brain volume loss, and 3-month CDW within 24 months in the FREEDOMS trial (table 3). Irrespective of treatment, patients with high blood NfL concentrations $(>60 \mathrm{pg} / \mathrm{mL})$ at baseline compared with those with low baseline $\mathrm{NfL}$ concentrations $(<30 \mathrm{pg} / \mathrm{mL})$ had 2.6 times more new or enlarging T2 lesions (difference: 164\%), 2.5 times more MS relapses (difference: 153\%), 2.9 times more brain volume loss (difference: 195\%) (all $p<0.001)$, and had a 1.9 times higher risk of 3-month CDW $(p=0.0605)$. Although fingolimod significantly reduced all these outcomes, there was no significant
treatment-by-NfL category interaction, suggesting that the prognostic value of NfL is applicable in both placebo- and fingolimod-treated patients, and that the treatment effects of fingolimod were consistent in all NfL categories.

\section{Discussion}

In this study, we measured plasma NfL levels using the highly sensitive SIMOA method in a large representative sample set of patients with RRMS, participating in 2 controlled, phase 3 trials. This setting not only allowed assessment of the relative effects of fingolimod treatment vs placebo and IFN- $\beta$ - $1 \mathrm{a}$ in a parallel randomized design, but it also provided the opportunity to study the relation of this specific marker of 
Figure 4 Effect of fingolimod on NfL levels in blood, (A) compared with placebo, FREEDOMS study; (B) compared with interferon- $\beta-1 a$, TRANSFORMS study

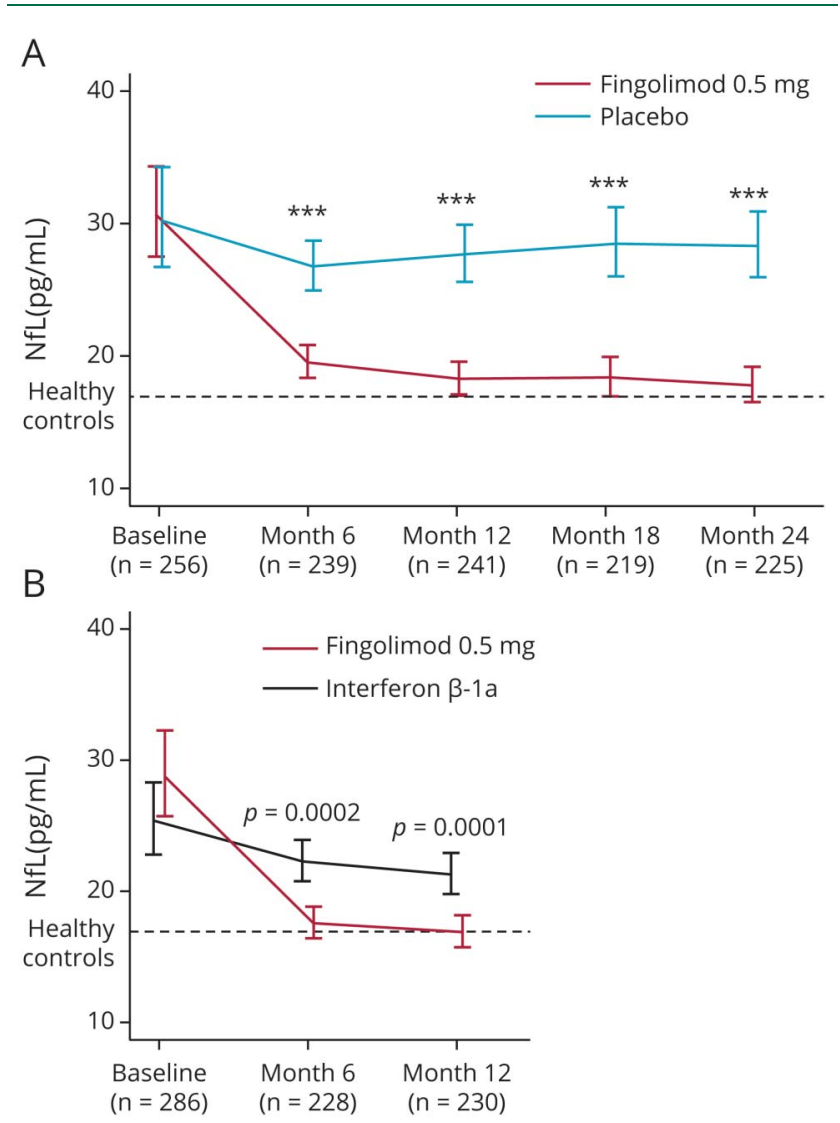

The figure shows geometric means of NfL with $95 \%$ confidence intervals and statistical tests from mixed models for repeated measurements of postbaseline NfL. Dotted line represents plasma $\mathrm{NfL}(\mathrm{pg} / \mathrm{mL}$, geometric mean) concentrations in healthy controls. ${ }^{\star \star}{ }^{\prime} p<0.0001 . \mathrm{n}=$ number of patients with evaluable data. $\mathrm{NfL}=$ neurofilament light chain.

neuroaxonal damage with other clinical and imaging measures of disease activity and severity obtained independently under good clinical practice conditions.

The patients included in our study were typical for an RRMS population. Although samples were only available for about $25 \%$ of all study participants, the selection criterion (patient's consent in the biomarker study) and the comparison of baseline characteristics of those included in this analysis from each of the 2 studies and the respective ITT population do not suggest any relevant selection bias. ${ }^{11,12}$

Baseline characteristics of the 2 trials were similar except for a higher number of $\mathrm{Gd}+$ lesions and higher $\mathrm{T} 2$ lesion volume in FREEDOMS than in TRANSFORMS. This difference probably reflects that TRANSFORMS patients were permitted to continue their previous disease-modifying treatment without washout - in contrast, interferon- $\beta$ or glatiramer acetate therapy had to have been stopped 3 or more months before randomization in the FREEDOMS trial. Similarly, NfL concentrations in patients were significantly higher than in healthy controls, confirming previous observations in CSF $^{14-18}$ and blood, ${ }^{4,6-9}$ but across the 2 trials, were lower in TRANSFORMS than in FREEDOMS. Plasma NfL levels at baseline were highly correlated with MRI markers of disease activity ( $\mathrm{Gd}+$ lesions and $\mathrm{T} 2$ lesion volume) and future tissue destruction (brain volume loss), and this close correlation was sustained throughout the studies irrespective of treatment.

Although patients with enhancing lesions had higher NfL levels, NfL levels in patients without Gd+ lesions were still significantly higher than levels in healthy individuals. This finding suggests that NfL levels also reflect ongoing neuronal damage and loss independent of detectable inflammatory activity, possibly occurring in normal-appearing gray and white matter. This assumption is further supported by the correlation between NfL levels and an objective measure of neuroaxonal damage, brain and spinal cord volume loss in a recent study by our group, ${ }^{9}$ and by the predictive value of baseline NfL for brain volume loss after 2 years on study in the FREEDOMS trial. Together, these results suggest that NfL in blood is likely to reflect an integral measure of recent and ongoing neuronal damage (over weeks, and possibly months). This neuronal damage not only relates to lesions in both white matter and gray matter regions but also the extralesional (normal-appearing) cortical gray matter MS pathology that manifests as reduction in density of both neurons and oligodendroglia in areas outside lesions.

The high correlation of plasma NfL levels with lesional MRI activity observed in this study is in accordance with the results of a recent observational study ${ }^{6}$ in which patients with high numbers of $\mathrm{T} 2$ or contrast-enhancing lesions in brain or spinal cord had higher serum NfL levels. This correlation of MRI activity with a specific marker of neuroaxonal damage adds to our understanding of the clinical-radiologic paradox in MS-the low correlation of MRI activity with clinical disability. ${ }^{19,20}$ The identification of T2 lesion load and presence of $\mathrm{Gd}+$ lesions as strong predictors of later brain volume $\operatorname{loss}^{21}$ has already informed the debate about the relevance of MRI activity but less convincingly because brain volume is also dependent on water content and therefore confounded by inflammatory edema and its resolution. Because of their specificity for neurons, increased NfL levels confirm that active inflammatory lesions are associated with neuroaxonal damage. The reasons for their low correlation with clinical disability must therefore primarily be sought in compensation and repair. Neuropathologic studies showing a higher rate of axonal damage in early/relapsing than in progressive MS brains are also compatible with this view. ${ }^{22}$

NfL levels at baseline had a prognostic value for future onstudy disease activity and progression on a group level. Irrespective of treatment allocation, in the FREEDOMS study, categorization of NfL levels into high vs low significantly increased the risk of new/enlarging T2 lesions, relapses, and accelerated brain volume loss over 2 years. 
Table 3 Clinical and MRI-related outcomes at month 24 by treatment and baseline NfL category (FREEDOMS)

\begin{tabular}{|c|c|c|c|c|c|c|c|c|c|}
\hline \multirow[b]{2}{*}{$\begin{array}{l}\text { Disease outcome } \\
\text { at EOS }\end{array}$} & \multicolumn{3}{|c|}{$\mathrm{NfL}$ category at baseline, $\mathrm{pg} / \mathrm{mL}$} & \multicolumn{2}{|c|}{$\begin{array}{l}\text { Treatment effect, } \\
\text { fingolimod vs } \\
\text { placebo }\end{array}$} & \multicolumn{2}{|c|}{ NfL effect, high vs low } & \multirow[b]{2}{*}{$\begin{array}{l}\text { Treatment } \\
\times \text { NfL, } \\
p \text { value }\end{array}$} & \multirow[b]{2}{*}{ Covariates } \\
\hline & $\begin{array}{l}\text { Low }<30 \\
(n=148)\end{array}$ & $\begin{array}{l}\text { Medium } \\
30-60 \\
(n=68)\end{array}$ & $\begin{array}{l}\text { High }>60 \\
(n=40)\end{array}$ & $\begin{array}{l}\text { Estimate } \\
(95 \% \mathrm{Cl}) \\
p \text { value }\end{array}$ & $\begin{array}{l}\% \\
\text { Diff }\end{array}$ & $\begin{array}{l}\text { Estimate } \\
(95 \% \mathrm{Cl}) \\
p \text { value }\end{array}$ & $\begin{array}{l}\% \\
\text { Diff }\end{array}$ & & \\
\hline \multicolumn{10}{|l|}{$\begin{array}{l}\text { No. of new/ } \\
\text { enlarging T2 } \\
\text { lesions, mean }\end{array}$} \\
\hline Fingolimod & 1.3 & 2.7 & 3.5 & \multirow{2}{*}{$\begin{array}{l}\text { Ratio of means } \\
0.21 \\
(0.15-0.30) \\
<0.0001^{a}\end{array}$} & \multirow[t]{2}{*}{-79} & \multirow{2}{*}{$\begin{array}{l}\text { Ratio of } \\
\text { means } 2.64 \\
(1.51-4.60) \\
0.0006^{\mathrm{a}}\end{array}$} & \multirow[t]{2}{*}{+164} & \multirow[t]{2}{*}{0.8298} & \multirow{2}{*}{$\begin{array}{l}\text { Sex, age, treatment, } \\
\text { baseline T2 lesion } \\
\text { volume }\end{array}$} \\
\hline Placebo & 5.8 & 12.5 & 19.0 & & & & & & \\
\hline \multicolumn{10}{|l|}{$\begin{array}{l}\text { Annual relapse } \\
\text { rate, mean }\end{array}$} \\
\hline Fingolimod & 0.1 & 0.2 & 0.6 & \multirow{2}{*}{$\begin{array}{l}\text { Annual relapse } \\
\text { rate ratio } \\
0.44 \\
(0.31-0.62) \\
<0.0001^{a}\end{array}$} & \multirow[t]{2}{*}{-56} & \multirow{2}{*}{$\begin{array}{l}\text { Annual } \\
\text { relapse rate } \\
\text { ratio } \\
2.53 \\
(1.67-3.83) ; \\
<0.0001^{a}\end{array}$} & \multirow[t]{2}{*}{+153} & \multirow[t]{2}{*}{0.2389} & \multirow{2}{*}{$\begin{array}{l}\text { Sex, age, treatment, } \\
\text { no. of relapses in } \\
\text { previous } 2 \text { y, EDSS } \\
\text { score }\end{array}$} \\
\hline Placebo & 0.5 & 0.3 & 1.24 & & & & & & \\
\hline
\end{tabular}

\section{Annualized rate}

of brain atrophy,

$\%$, mean

\begin{tabular}{|c|c|c|c|c|c|c|c|c|c|}
\hline Fingolimod & -0.362 & -0.583 & -1.127 & \multirow{2}{*}{$\begin{array}{l}\text { Difference of } \\
\text { means } \\
0.18 \\
(0.03-0.34) ; \\
0.0207^{a}\end{array}$} & \multirow[t]{2}{*}{-21} & \multirow{2}{*}{$\begin{array}{l}\text { Difference of } \\
\text { means } \\
-0.78 \\
(-1.02--0.54) ; \\
<0.0001^{\mathrm{a}}\end{array}$} & \multirow[t]{2}{*}{+195} & \multirow[t]{2}{*}{0.2554} & \multirow{2}{*}{$\begin{array}{l}\text { Sex, age, treatment, } \\
\text { baseline normalized } \\
\text { brain volume }\end{array}$} \\
\hline Placebo & -0.502 & -0.954 & -1.362 & & & & & & \\
\hline
\end{tabular}

Time to CDW,

month 24 Kaplan-

Meier estimate, \%

\begin{tabular}{|c|c|c|c|c|c|c|c|c|c|}
\hline Fingolimod & 9.5 & 7.5 & 23.3 & \multirow{2}{*}{$\begin{array}{l}\text { Hazard ratio } \\
0.33 \\
(0.18-0.63) ; \\
0.0006^{\mathrm{a}}\end{array}$} & \multirow[t]{2}{*}{-67} & \multirow{2}{*}{$\begin{array}{l}\text { Hazard ratio } \\
1.94 \\
(0.97-3.87) \\
0.0605^{a}\end{array}$} & \multirow[t]{2}{*}{+94} & \multirow[t]{2}{*}{0.5158} & \multirow{2}{*}{$\begin{array}{l}\text { Sex, age, treatment } \\
\text { EDSS score }\end{array}$} \\
\hline Placebo & 27.1 & 32.1 & 39.0 & & & & & & \\
\hline
\end{tabular}

Abbreviations: $\mathrm{CDW}=$ confirmed disability worsening; $\mathrm{Cl}=$ confidence interval; EDSS = Expanded Disability Status Scale; EOS = end of study; NfL = neurofilament light chain; \%Diff = percentage difference.

Outcome shown in each category is raw mean. The \% change, estimates, and $95 \% \mathrm{Cl}$ with $p$ values are from statistical models. The number of new or enlarging T2 lesions and the annual relapse rate were analyzed in negative binomial models, the annualized rate of brain atrophy (\%) in a multiple linear regression model, and time to 3-month CDW in a Cox proportional hazard model. The main effect estimates and $p$ values for treatment and NfL levels are from a statistical model with the mentioned covariates; the $p$ value for the treatment-by-NfL interaction is from an extended model with interaction term. The \% change for the "treatment effect" and the corresponding $p$ value refer to the relative change in the disease outcome in fingolimod-treated patients as compared with placebo when adjusting for the NfL category and all other covariates in the model. The \% change for the "NfL effect" and the corresponding $p$ value refer to the relative change in the disease outcome in "high" vs "low" NfL when adjusting for treatment and all other covariates in the respective model. All \% change estimates are directly from the statistical model (rate ratio or hazard ratio minus 1, expressed as a percentage), with the exception of the annualized rate of brain atrophy. For the annualized rate of brain atrophy, the difference of mean is calculated from least squares mean (data not shown). The $\%$ difference was estimated; difference of means divided by the least squares mean in the reference category (placebo or NfL "low" category). Treatment $\times$ $\mathrm{NfL}$ : a nonsignificant interaction term means that the NfL effect is applicable for both treatment arms, and the fingolimod treatment effect is applicable across all baseline NfL categories.

${ }^{\text {a }}$ Significant.

Association with CDW was not significant but in the same direction. A small study in serum ${ }^{7}$ and 2 studies in $\mathrm{CSF}^{3,23}$ also described the prognostic value of NfL for later brain volume loss. This has also recently been confirmed and extended to spinal cord volume loss in a large observational study. ${ }^{9}$ However, further research is needed to understand whether NfL may allow treatment decisions on an individual patient basis.

In contrast to 3 recent studies that reported treatment effects of disease-modifying therapies on blood NfL levels in observational settings, ${ }^{6-9}$ the parallel controlled study design of
FREEDOMS and TRANSFORMS allowed controlling for potential spontaneous remission ("regression to the mean") and therefore provided a reliable estimate of fingolimod's effect. In both of these parallel controlled studies, fingolimod treatment was associated with significantly lower NfL levels than the comparators, placebo, or IFN- $\beta-1 \mathrm{a}$, and this effect was seen from the first measurement at 6 months until the end of the studies.

We have shown that blood NfL levels are closely related to clinical and MRI measures in patients with RRMS, which 
capture features of acute disease activity, worsening of disability, and tissue loss. In contrast to imaging markers, it is feasible to measure blood NfL serially, with minimal burden to the patient. NfL levels in blood appear suitable to monitor disease activity and drug response in real time. In the future, with the availability of a normative database containing reference ranges for NfL levels that take into account the agedependent increase of blood NfL in healthy controls and more data about the effects of comorbidities, NfL could also inform treatment decisions at the individual level.

\section{Author contributions}

J. Kuhle: literature search, figures, data generation, data analysis, data interpretation, writing. H. Kropshofer: literature search, study design and data interpretation, writing and critical review of manuscript. D.A. Haering: data analysis and interpretation, and critical review of manuscript. U. Kundu: literature search, manuscript drafting, revising and editing. R. Meinert: statistical analysis, figures, and manuscript review. C. Barro: literature search, data generation and data interpretation, critical review of manuscript. F. Dahlke, D. Tomic, and D. Leppert: study design, data interpretation, and critical review of the manuscript. L. Kappos: study design, data collection and data interpretation, and critical review of manuscript.

\section{Study funding}

The study was funded by Novartis Pharma AG and the Swiss National Science Foundation (320030_160221). The study sponsor (Novartis Pharma AG) participated in the design and conduct of the study, data collection, data management, data analysis and interpretation, and preparation, review, and approval of the manuscript. The measurement of NfL levels was performed (by fully blinded staff) at the University Hospital, Basel, Switzerland, and the data were provided to the sponsor. The biostatistical analyses were done at DATAMAP, Freiburg, Germany.

\section{Disclosure}

J. Kuhle's institution (University Hospital Basel) received and exclusively used for research support: consulting fees from Biogen, Novartis, Protagen AG, Roche, and Teva; speaker fees from the Swiss MS Society, Biogen, Genzyme, Merck, Novartis, Roche; travel expenses from Merck Serono, Novartis, and Roche; and grants from the ECTRIMS Research Fellowship Programme, University of Basel, Swiss MS Society, Swiss National Research Foundation (320030_160221), Bayer, Biogen, Genzyme, Merck, Novartis, and Roche. H. Kropshofer is an employee of Novartis Pharma AG. D. Haering is an employee of Novartis Pharma AG. U. Kundu is an employee of Novartis Healthcare. R. Meinert is an employee of DATAMAP GmbH, Freiburg, Germany, which provides services to Novartis Pharma AG. C. Barro received travel support from Teva and Novartis. F. Dahlke is an employee of Novartis Pharma AG. D. Tomic is an employee of Novartis Pharma AG. D. Leppert is an employee of Novartis Pharma AG. L. Kappos' institution (University Hospital Basel) has received in the last 3 years and used exclusively for research support: steering committee, advisory board, and consultancy fees from Actelion, Addex, Bayer
HealthCare, Biogen Idec, Biotica, Genzyme, Lilly, Merck, Mitsubishi, Novartis, Ono Pharma, Pfizer, Receptos, Sanofi, Santhera, Siemens, Teva, UCB, and XenoPort; speaker fees from Bayer HealthCare, Biogen Idec, Merck, Novartis, Sanofi, and Teva; support for educational activities from Bayer HealthCare, Biogen, CSL Behring Genzyme, Merck, Novartis, Sanofi, and Teva; license fees for Neurostatus products; and grants from Bayer HealthCare, Biogen Idec, European Union, Merck, Novartis, Roche Research Foundation, Swiss MS Society, and the Swiss National Research Foundation. Go to Neurology.org/ $\mathrm{N}$ for full disclosures.

\section{Publication history}

Received by Neurology February 2, 2018. Accepted in final form November 2, 2018.

\section{References}

1. Wattjes MP, Rovira À, Miller D, et al. Evidence-based guidelines: MAGNIMS consensus guidelines on the use of MRI in multiple sclerosis: establishing disease prognosis and monitoring patients. Nat Rev Neurol 2015;11:597-606.

2. Saindane AM, Law M, Ge Y, Johnson G, Babb JS, Grossman RI. Correlation of diffusion tensor and dynamic perfusion MR imaging metrics in normal-appearing corpus callosum: support for primary hypoperfusion in multiple sclerosis. AJNR Am J Neuroradiol 2007;28:767-772.

3. Arrambide G, Espejo C, Eixarch H, et al. Neurofilament light chain level is a weak risk factor for the development of MS. Neurology 2016;87:1076-1084.

4. Kuhle J, Barro C, Disanto G, et al. Serum neurofilament light chain in early relapsing remitting MS is increased and correlates with CSF levels and with MRI measures of disease severity. Mult Scler 2016;22:1550-1559.

5. Kuhle J, Nourbakhsh B, Grant D, et al. Serum neurofilament is associated with progression of brain atrophy and disability in early MS. Neurology 2017;88:826-831.

6. Disanto G, Barro C, Benkert P, et al. Serum neurofilament light: a biomarker of neuronal damage in multiple sclerosis. Ann Neurol 2017;81:857-870.

7. Piehl F, Kockum I, Khademi M, et al. Plasma neurofilament light chain levels in patients with MS switching from injectable therapies to fingolimod. Mult Scler 2018; 24:1046-1054.

8. Novakova L, Zetterberg H, Sundström P, et al. Monitoring disease activity in multiple sclerosis using serum neurofilament light protein. Neurology 2017;89:2230-2237.

9. Barro C, Benkert P, Disanto G, et al. Serum neurofilament light chain as a predictor of disease worsening and brain and spinal cord atrophy in multiple sclerosis. Brain Epub 2018 May 30.

10. Gisslen M, Price RW, Andreasson U, et al. Plasma concentration of the neurofilament light protein (NfL) is a biomarker of CNS injury in HIV infection: a cross-sectional study. EBioMedicine 2016;3:135-140.

11. Kappos L, Radue EW, O'Connor P, et al. A placebo-controlled trial of oral fingolimod in relapsing multiple sclerosis. N Engl J Med 2010;362:387-401.

12. Cohen JA, Barkhof F, Comi G, et al. Oral fingolimod or intramuscular interferon for relapsing multiple sclerosis. N Engl J Med 2010;362:402-415.

13. De Stefano N, Silva DG, Barnett MH. Effect of fingolimod on brain volume loss in patients with multiple sclerosis. CNS Drugs 2017;31:289-305.

14. Norgren N, Sundström P, Svenningsson A, Rosengren L, Stigbrand T, Gunnarsson M. Neurofilament and glial fibrillary acidic protein in multiple sclerosis. Neurology 2004; 63:1586-1590.

15. Teunissen CE, Iacobaeus $\mathrm{E}$, Khademi M, et al. Combination of CSF $\mathrm{N}$-acetylaspartate and neurofilaments in multiple sclerosis. Neurology 2009;72:1322-1329.

16. Gunnarsson M, Malmeström C, Axelsson M, et al. Axonal damage in relapsing multiple sclerosis is markedly reduced by natalizumab. Ann Neurol 2011;69:83-89.

17. Romme Christensen J, Börnsen L, Khademi M, et al. CSF inflammation and axonal damage are increased and correlate in progressive multiple sclerosis. Mult Scler 2013;19:877-884.

18. Novakova L, Axelsson M, Khademi M, et al. Cerebrospinal fluid biomarkers as a measure of disease activity and treatment efficacy in relapsing-remitting multiple sclerosis. J Neurochem 2017;141:296-304.

19. Kappos L, Moeri D, Radue EW, et al. Predictive value of gadolinium-enhanced magnetic resonance imaging for relapse rate and changes in disability or impairment in multiple sclerosis: a meta-analysis. Gadolinium MRI Meta-analysis Group. Lancet 1999;353:964-969.

20. Barkhof F. The clinico-radiological paradox in multiple sclerosis revisited. Curr Opin Neurol 2002;15:239-245.

21. Radue EW, Barkhof F, Kappos L, et al. Correlation between brain volume loss and clinical and MRI outcomes in multiple sclerosis. Neurology 2015;84:784-793.

22. Kuhlmann T, Lingfeld G, Bitsch A, Schuchardt J, Brück W. Acute axonal damage in multiple sclerosis is most extensive in early disease stages and decreases over time. Brain 2002; 125:2202-2212.

23. Petzold A, Steenwijk MD, Eikelenboom JM, Wattjes MP, Uitdehaag BM. Elevated CSF neurofilament proteins predict brain atrophy: a 15-year follow-up study. Mult Scler 2016;22:1154-1162. 


\section{Neurology}

\section{Blood neurofilament light chain as a biomarker of MS disease activity and treatment response}

Jens Kuhle, Harald Kropshofer, Dieter A. Haering, et al.

Neurology 2019;92;e1007-e1015 Published Online before print February 8, 2019

DOI 10.1212/WNL.0000000000007032

This information is current as of February 8, 2019

\section{Updated Information \&} Services

References

Citations

Subspecialty Collections

Permissions \& Licensing

Reprints including high resolution figures, can be found at: http://n.neurology.org/content/92/10/e1007.full

This article cites 22 articles, 6 of which you can access for free at: http://n.neurology.org/content/92/10/e1007.full\#ref-list-1

This article has been cited by 6 HighWire-hosted articles: http://n.neurology.org/content/92/10/e1007.full\#\#otherarticles

This article, along with others on similar topics, appears in the following collection(s):

MRI

http://n.neurology.org/cgi/collection/mri

Multiple sclerosis

http://n.neurology.org/cgi/collection/multiple_sclerosis

Information about reproducing this article in parts (figures,tables) or in its entirety can be found online at:

http://www.neurology.org/about/about_the_journal\#permissions

Information about ordering reprints can be found online: http://n.neurology.org/subscribers/advertise

Neurology $®$ is the official journal of the American Academy of Neurology. Published continuously since 1951, it is now a weekly with 48 issues per year. Copyright Copyright @ 2019 The Author(s). Published by Wolters Kluwer Health, Inc. on behalf of the American Academy of Neurology.. All rights reserved. Print ISSN: 0028-3878. Online ISSN: 1526-632X.

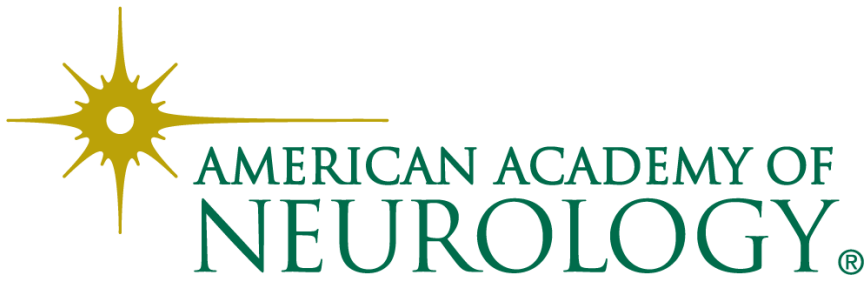

